\title{
Amiodarone-induced exudative bullous lesion and hepatotoxicity in a patient with ventricular tachycardia
}

\author{
Ahmet Karakurt ${ }^{\mathrm{a}, *}$, Cennet Yildiz ${ }^{\mathrm{b}}$, Abdülmelik Yildiz ${ }^{\mathrm{c}}$, Hamit Serdar Başbuğ ${ }^{\mathrm{d}}$ \\ a Department of Cardiology, Kafkas University Faculty of Medicine, Kars, Turkey \\ b Department of Cardiology, Tekden Hospital, İstanbul, Turkey \\ c Department of Cardiology, Asya Hospital, İstanbul, Turkey \\ d Department of Cardiovascular Surgery, Kafkas University Faculty of Medicine, Kars, Turkey
}

\section{A R T I C L E I N F O}

\section{Article history:}

Received 8 August 2015

Accepted 9 October 2015

Available online 18 October 2015

Keywords:

Exudative bullous lesions

Hepatotoxicity

Amiodarone side effects

\begin{abstract}
A B S T R A C T
Amiodarone is a potent, iodine rich, highly lipophilic class III antiarrhythmic drug widely used for the management of both supraventricular and ventricular arrhythmias. It tends to concentrate in tissues including fat, lung, liver cornea and skin. Several side effects have been reported in patients taking amiodarone. The mechanisms of amiodarone-induced side effects are poorly understood. Accumulation of amiodarone in tissues and organs has been suggested as a possible mechanism. The most frequent dermatologic side effects are photosensitivity, skin discoloration and erythema. This article presents the case of a patient who developed amiodaroneinduced bullous skin lesions and hepatotoxicity.

(C) 2015 The Society of Cardiovascular Academy. Production and hosting by Elsevier B.V. All rights reserved. This is an open access article under the CC BY-NC-ND license (http://creativecommons.org/licenses/by-nc-nd/4.0/).
\end{abstract}

\section{Introduction}

Amiodarone is considered as a class III antiarrythmic (Vaughan Williams classification). It possesses electrophysiologic characteristics of sodium, potassium and calcium channel blockage, as well as alpha and beta adrenergic blocking activity. ${ }^{1,2}$ It is commonly used in the treatment of supraventricular and ventricular arrhythmias, such as atrial fibrillation and ventricular tachycardia. ${ }^{3}$ It has strong antiarrythmic properties but may cause neurologic, pulmonary, thyroid, ocular, dermatologic, and hepatic toxicity in long-term or excessive use. The mechanisms of side effects are not well understood. The most common side effects of amiodarone are nausea and vomiting, which occur in approximately $25 \%$ of patients. Side effects of the skin are also common, occurring in approximately $15 \%$ of patients. ${ }^{4}$ Patients frequently experience photosensitivity. Other dermatological side effects of amiodarone include skin discoloration and blue-gray or yellow-brown pigmentation. In this report, we present a case of ventricular tachycardia that developed erythematous exudative bullous skin lesions and hepatotoxicity during amiodarone therapy.

\footnotetext{
* Corresponding author. Tel.: +90 505 2556152; fax: +90 4742251193.

E-mail address: karakurt38@hotmail.com (A. Karakurt).

Peer review under responsibility of The Society of Cardiovascular Academy.
}

\section{Case presentation}

Sixty-one year old male patient was admitted to the emergency department with complaints of palpitation, dyspnea and chest pain. He had the same symptoms twice in the last $24 \mathrm{~h}$. He denied any syncope or dizziness. He had a history of hypertension and a coronary angiography which was performed 2 years ago. The angiogram showed slow flow in the coronary arteries without any other coronary pathology. The patient was treated with acetylsalicylic acid (ASA) and antihypertensive medications.

The patient had a hemodynamically stable ventricular tachycardia. The remaining systemic examination was normal.

Electrocardiography (ECG) showed sinus rhythm in leads I-III, aVR, $\mathrm{AVL}$, and AVF at initial recording. The rest of the ECG revealed monomorphic, monofocal ventricular tachycardia (VT). The rhythm on cardiac monitor was consistent with VT (Fig. A). Hemogram and biochemical parameters were within normal limits.

Two-dimensional (2-D) echocardiography was performed after medical cardioversion and cardiac measurements were determined by 2D, cross sectional M mode and Doppler study echocardiography. Echocardiographic measurements as follows: right ventricle diameter: $1.9 \mathrm{~cm}$, left ventricular end-diastolic diameter: $4.5 \mathrm{~cm}$, interventricular septum diastolic diameter: $1.4 \mathrm{~cm}$, and the left ventricular posterior wall diastolic diameter: $1.2 \mathrm{~cm}$. Left ventricular ejection fraction was calculated as $58 \%$ by using the modified Simpson technique. There was no valvular, supravalvular or infravalvular stenosis in the aorta and pulmonary artery. 


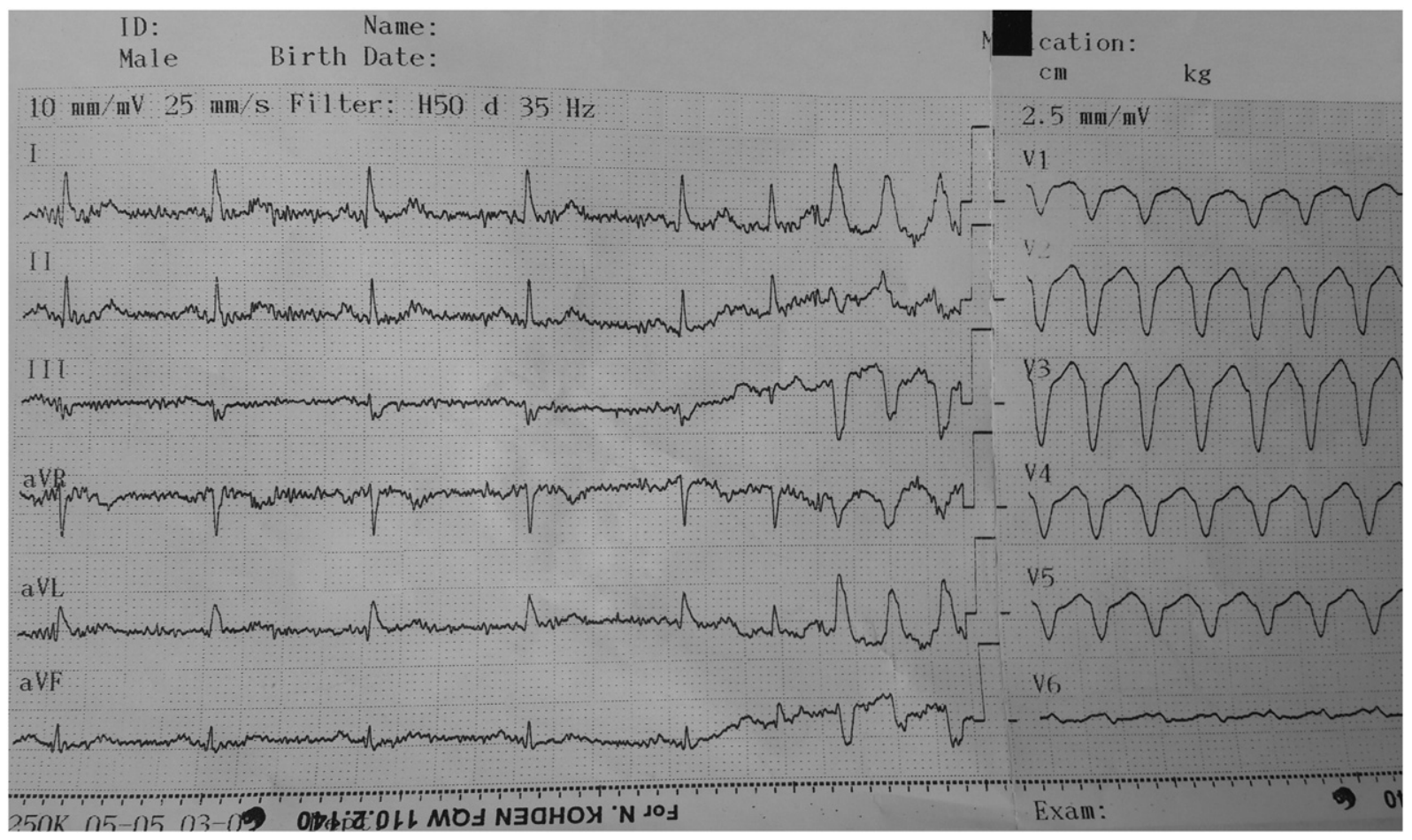

Fig. A. 12-Lead surface ECG during ventricular tachycardia.

The patient was diagnosed with sustained VT. Due to patient's stable clinical and hemodynamic parameters it was decided that a medical cardioversion was required. After loading dose of amiodarone, (150 mg in $100 \mathrm{~mL}$ dextrose (D5W) administered over $10 \mathrm{~min}$ ), the patient was returned to sinus rhythm. His dyspnea and palpitations disappeared. The patient was taken to the coronary care unit and therapy was continued with a slow loading infusion containing $900 \mathrm{mg}$ amiodarone injection in $500 \mathrm{~mL}$ of dextrose (D5W). The infusion was administered at a rate of $1 \mathrm{mg} / \mathrm{min}$ for $6 \mathrm{~h}$ followed by maintenance infusion at a rate of $0.5 \mathrm{mg} / \mathrm{min}$ over $18 \mathrm{~h}$.

Coronary angiography revealed ectasia in the proximal and mid portions of the LAD and Cx with no critical obstructive lesions. There was also slow flow in both coronary arteries.

One day later, the patient had elevated liver enzymes and developed multiple bullous skin lesions over the anterior chest wall filled with exudative material. All bullae appeared on slightly erythematous base. Diameters of the largest and the smallest bulla were $2.3 \times 1.5 \mathrm{~cm}$ and $0.6 \times 0.7 \mathrm{~cm}$ respectively. Erythema was more prominent around the hair follicles and occurred both on the normal and involved skin (Figs. B and C). The biochemistry and hemogram results were as follows: Alanine transaminase (ALT) $99 \mathrm{U} / \mathrm{L}$ (normal $<41 \mathrm{U} / \mathrm{L}$ ), aspartate transaminase (AST) $89 \mathrm{U} / \mathrm{L}$ (normal $<40 \mathrm{U} / \mathrm{L}$ ), lactate dehydrogenase $(\mathrm{LDH}) 210 \mathrm{U} / \mathrm{L}$ (normal $135-225 \mathrm{U} / \mathrm{L}$ ), monocyte $0.59 \mathrm{c} / \mu \mathrm{L}$ (normal $0.12-1.2 \mathrm{c} / \mu \mathrm{L}$ ) and basophiles $0.08 \mathrm{c} / \mu \mathrm{L}$ (normal $0.00-0.02 \mathrm{c} / \mu \mathrm{L}$ ). The results of other laboratory tests were within normal limits.

Amiodarone was stopped and the patient was started on propafenone (class Ic antiarrhythmic agent) orally every $12 \mathrm{~h}$. During the follow-up, no VT or other arrhythmia was observed and liver enzymes returned to normal. He was discharged on the sixth day of hospitalization with prescriptions of acetylsalicylic acid $100 \mathrm{mg}$ $1 \times 1$, propafenone $150 \mathrm{mg} 2 \times 1$ and valsartan $160 \mathrm{mg} 1 \times 1$. One month later, at the follow-up visit, the patient noted that his symptoms had subsided. The patient's biochemical, hemogram and ECG results were normal. Bullae healed leaving scar tissue (Fig. D).
Twenty four hour holter monitoring showed no pathological findings.

\section{Discussion}

Amiodarone is probably one of the most potent antiarrhythmic medications that we have available. Unfortunately, it also has side effects; up to $40 \%$ of patients quit amiodarone within 2 years due to those side effects. ${ }^{1,5,6}$ It is metabolized in the liver by cytochrome p450 enzymes and excreted in the bile. Less than $1 \%$ of the dose excreted in the urine. ${ }^{7}$ Its main metabolite, desethylamiodarone, has also multiple side effects. ${ }^{8}$ The mechanisms of side effects are not fully understood. Side effects include photosensitivity ( $25 \%$ to $75 \%$ ), blue-gray or yellow-brown skin discoloration located mostly on the face, ears, and palms of the hands ( $4 \%$ to $9 \%$ ), hepatotoxicity (15\% to $30 \%$ ); optic neuropathy/neuritis ( $1 \%$ to $2 \%$ ), corneal microdepsits (>90\%), pulmonary toxicity (1\% to $17 \%$ ), hypothyroidism (6\%), hyperthyroidism ( $0.9 \%$ to $2 \%$ ), tremor and ataxia ( $3 \%$ to $35 \%)$. ${ }^{3}$ Peripheric neuropathy, insomnia, memory loss and delirium are uncommon side effects that have been reported in the literature. Life-threatening anaphylaxis or anaphylactoid reaction, pulmonary alveolitis and fibrosis have been reported., ${ }^{2,9}$

Our patient had elevated liver enzyme levels and multiple bullae. Bullae filled with no purulent fluid resembling exudates. Light microscopic skin examination revealed normal epidermis. The HematoxylinEosin-Saffron stained sections demonstrated few yellow brown granules within cytoplasm of histiocytes in the mid dermis. These pigmented histiocytes clustered around capillaries. Minimal inflammation was observed. Histochemically the pigments were strongly positive by Ziehl-Neelsen, mild to moderate positive by PAS and negative by turnbull blue stainings. ${ }^{10,11}$

Electron microscopy revealed polygonal to fusiform shaped histiocytes with large cytoplasm, dispersed between dermal collagen fibers. Spheroid and extended nucleolus with dense chromatin network and large cytoplasm contained dense bodies ranging in size from 250 to $2500 \mathrm{~nm}$, dense granules and eosinophilic materials. No difference 


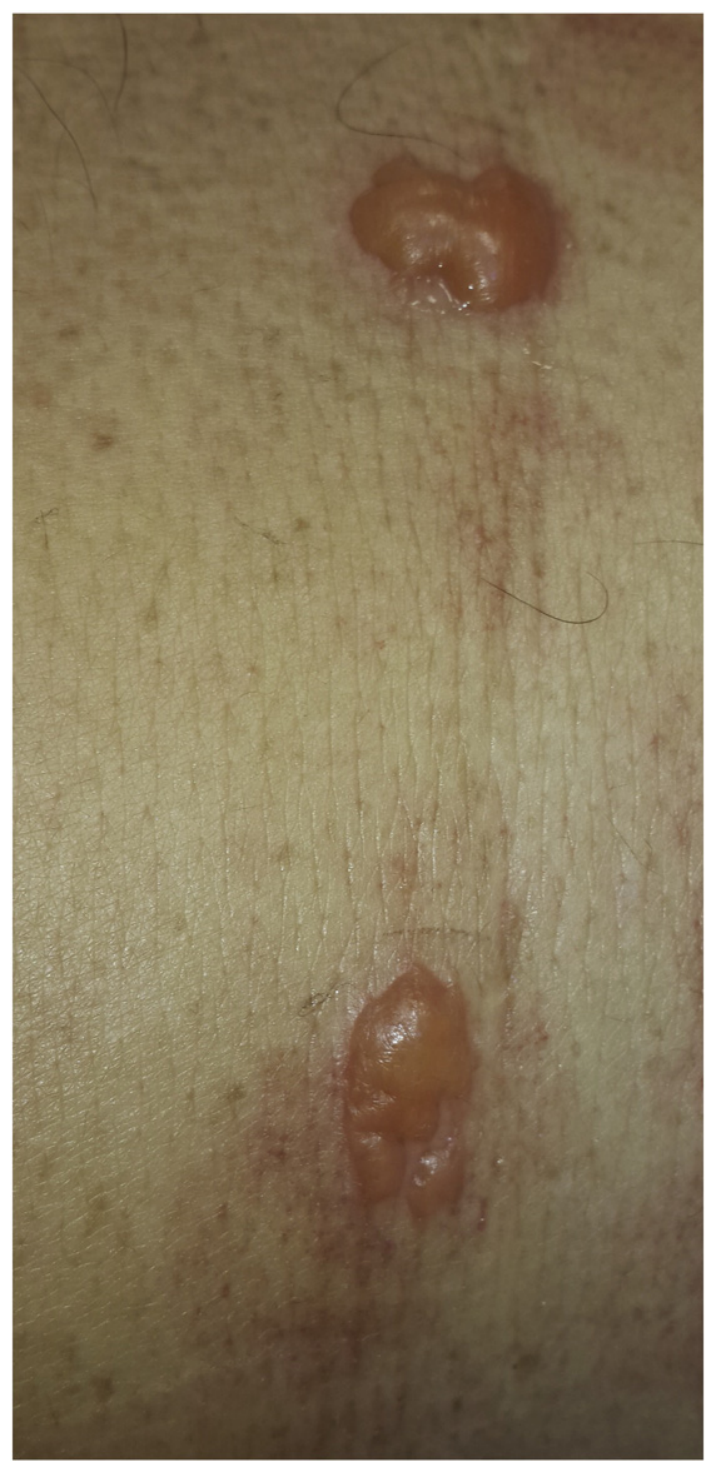

Fig. B. Multiple bullous lesions filled with material resembling exuda.

was reported in the other organelles including mitochondria, endoplasmic reticulum and free ribosomes. ${ }^{10,11}$

Dermatological complications of amiodarone are time-and dosedependent. In most cases adverse effects are reversible with discontinuation of therapy. The main skin changes induced by amiodarone are phototoxic and photoallergic reactions, as well as hyperpigmentation. More than $10 \%$ of patients have been reported to have sunlight sensitivity. The symptoms begin in several minutes after exposure to the sunlight, continue up to $24 \mathrm{~h}$ and usually subside in approximately $48 \mathrm{~h}$, but in some cases they persist up to $72 \mathrm{~h}$. Phototoxic and photoallergic reactions might even occur a few months after the withdrawal of amiodarone due to its long elimination time. ${ }^{12}$ During long-term or highdosage amiodarone therapy, patients should be recommended to protect themselves against photosensitivity. Patients should wear lightweight clothing that covers most surface areas of skin and use sunscreen to protect themselves from harmful UV-A/UV-B radiation. ${ }^{3}$

Blue-gray discoloration of the skin is an uncommon adverse effect caused by the accumulation of lipofuscin and melatonin in dermis. ${ }^{13}$ The appearance of the discoloration depends on the dosage of amiodarone and duration of use, and may regress upon cessation of the treatment. ${ }^{14}$ Biopsy confirms skin impregnation of iodine with deposition of brown pigment within dermal microphages. Occurrence of skin

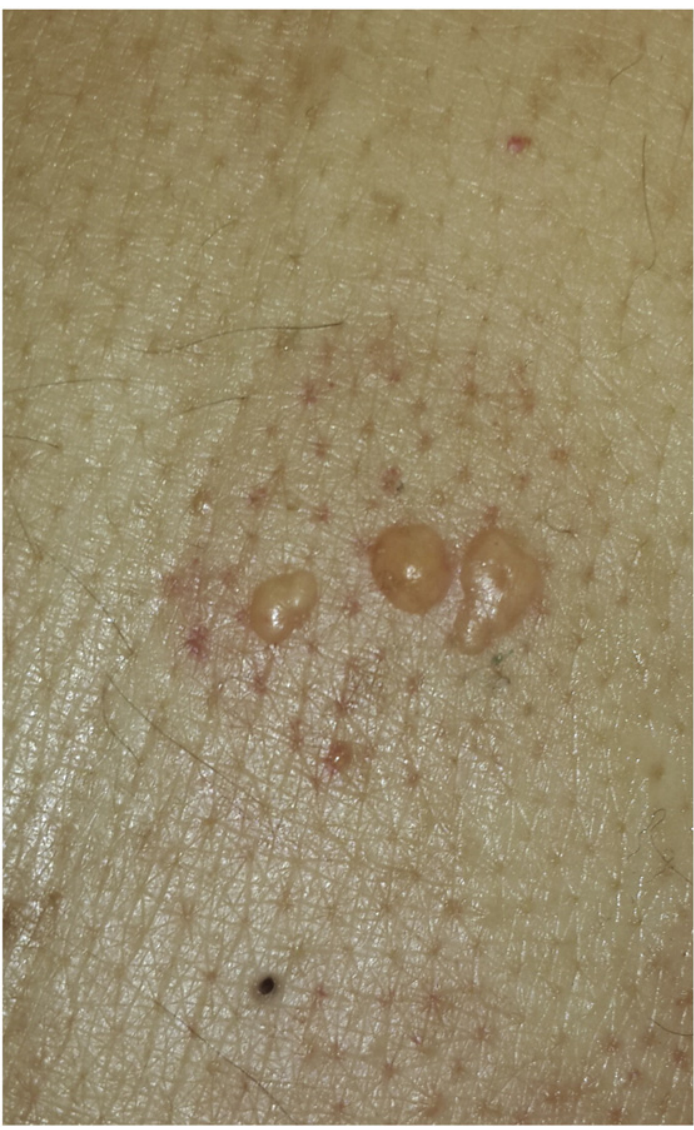

Fig. C. Multiple bullous lesions filled with material resembling exuda.

lesions does not require discontinuation of therapy. Treatment should be stopped if liver enzyme levels exceed three times the upper limit of normal. ${ }^{15}$

The amiodarone molecule contains a large amount of inorganic iodine, which may exacerbate certain skin diseases, such as dermatitis herpetiformis and psoriasis. There have been reports of postamiodarone pseudo-purulent changes, such as acne or blisterpurulent lesions characteristic of iodism. ${ }^{12,16}$ Less common dermatological complications of amiodarone include hives, pruritus, erythema nodosum, purpura, and the most severe variant of erythema multiforme-toxic epidermal necrolysis. ${ }^{17,18}$

Amiodarone can induce allergic reactions in sensitized patients. Although the mechanisms of allergic reaction to amiodarone are poorly understood, it is believed to occur due to the $37.3 \%$ iodine that is present in the amiodarone molecule. The incidence of amiodarone induced hypersensitivity reactions in hospitalized patients with a listed allergy to iodine or iodinated contrast agents was found to be $0.4 \%{ }^{19}$ Physicians should be cautious while prescribing amiodarone for such patients.

\section{Conclusion}

Amiodarone is a potent antiarrhythmic agent that is used to treat ventricular and supraventricular arrhythmias. Side effects due to amiodarone are related to dosage and route of administration. Skin lesions are common side effects of amiodarone therapy and do not require discontinuation of treatment. Treatment should be stopped if patients develop hepatotoxicity or liver enzyme elevations greater than the triple normal limit. It should be kept in mind that exudative bullous skin lesions may occur during amiodarone therapy. 


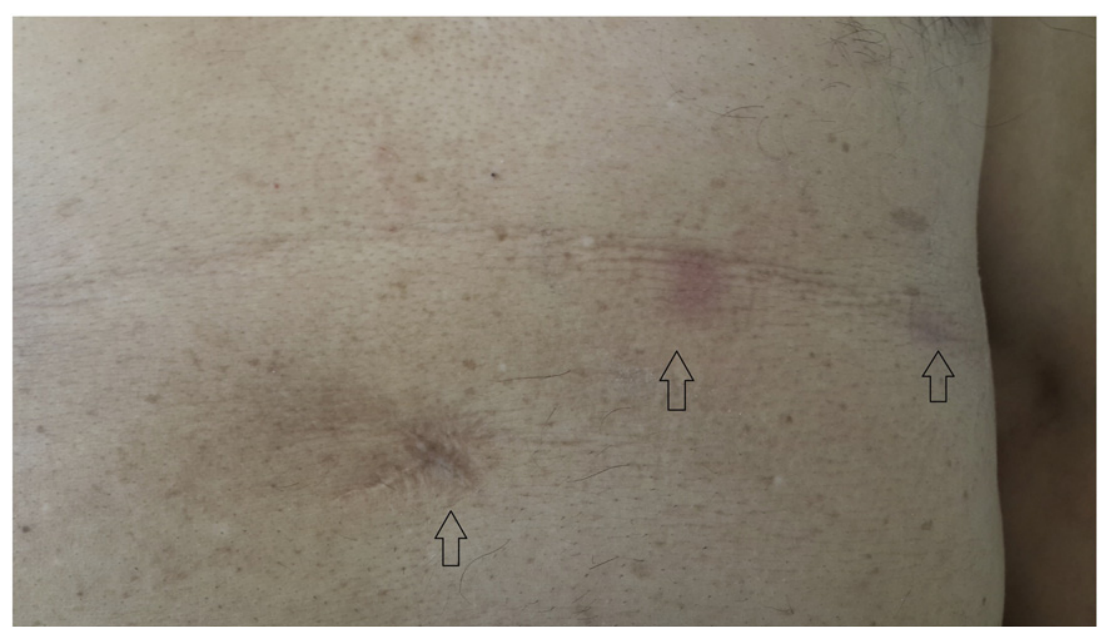

Fig. D. At one month follow-up visit, the patient showed healed bullae with scarring (black arrows).

\section{Conflict of interest}

None declared.

\section{References}

1. Aronson JK. Amiodarone. In: Dukes MNG, editor. Meyler's Side Effects of Drugs: The International Encyclopedia of Adverse Drug Reactions and Interactions. 15th ed. Oslo: Elsevier; 2006. p. 148-173.

2. Burches E, Garcia-Verdegay F, Ferrer M, Pelaez A. Amidarone-induced angioedema. Allergy 2000;55:1199-2000.

3. Vassallo P, Trohman RG. Prescribing amiodarone: an evidence-based review of clinical indications. JAMA 2007;298:1312-1322.

4. Rappersberger K, Hönigsmann H, Ortel B, Tanew A, Konrad K, Wolff K. Photosensitivity and hyperpigmentation in amiodarone-treated patients: incidence, time course and recovery. I Invest Dermatol 1989;93:201-209.

5. Côté P, Bourassa MG, Delaye J, Janin A, Froment R, David P. Effects of amiodarone on cardiac and coronary hemodynamics and on myocardial metabolism in patients with coronary artery disease. Circulation 1979;59:1165-1172.

6. Razavi M. Safe and effective pharmacologic management of arrhythmias. Tex Heart Inst J 2005;32:209-211.

7. 6Latini R, Tognoni G, Kates RE. Clinical pharmacokinetics of amiodarone. Clin Pharmacokinet 1984:9:136-156.

8. Dusman RE, Stanton MS, Miles WM, Klein LS, Zipes DP, Fineberg NS, et al. Clinical features of amiodarone-induced pulmonary toxicity. Circulation 1990;82:51-59.
9. Chrysanthopopoulos C, Siablis D, Kounis N. Amiodaroneinduced recurrent allergic pneumonitis. Ann Allergy 1988:60:111-114.

10. Delage C, Lagacé R, Huard J. Pseudocyanotic pigmentation of the skin induced by amiodarone: a light and electron microscopic study. Can Med Assoc J 1975;112: 1205-1208.

11. Zachary CB, Slater DN, Holt DW, Storey GC, MacDonald DM. The pathogenesis of amiodarone-induced pigmentation and photosensitivity. Br J Dermatol 1984;110: 451-456.

12. Jaworski K, Walecka I, Rudnicka L, Gnatowski M, Kosior DA. Cutaneous adverse reactions of amiodarone. Med Sci Monit 2014;20:2369-2372.

13. Roberts M. Clinical utility and adverse effects of amiodarone therapy. AACN Adv Crit Care 2010;21:333-338.

14. Siddoway LA. Amiodarone: guidelines for use and monitoring. Am Fam Physician 2003;68:2189-2196.

15. Harris L, McKenna WJ, Rowland E, Holt DW, Storey GCA, Krikler DM. Side effects of long-term amiodarone therapy. Circulation 1983;67:45-51.

16. Abel EA, DiCicco LM, Orenberg EK, et al. Drugs in exacerbation of psoriasis. J Am Acad Dermatol 1986;15:1007-1022.

17. Bencini PL, Crosti C, Sala F, et al. Toxic epidermal necrolysis and amiodarone treatment. Arch Dermatol 1985;121:838.

18. Yung A, Agnew K, Snow J, Oliver F. Two unusual cases of toxic epidermal necrolysis. Australas J Dermatol 2002;43:35-38.

19. Lakshmanadoss U, Lindsley J, Glick D, Twilley CH, Lewin 3rd JJ, Marine JE. Incidence of amiodarone hypersensitivity in patients with previous allergy to iodine or iodinated contrast agents. Pharmacotherapy 2012;32:618-622. 